\title{
Safe Opioid Storage and Disposal: A Survey of Patient Beliefs and Practices
}

This article was published in the following Dove Press journal:

Journal of Pain Research

\author{
Razmic Gregorian' \\ Elizabeth Marrett $\mathbb{D}^{2}$ \\ Vivek Sivathanu' \\ Mariana Torgal (1) \\ Sejal Shah' \\ Winghan Jacqueline Kwong ${ }^{2}$ \\ Jeffrey Gudin ${ }^{3}$ \\ 'Simon-Kucher \& Partners, Cambridge, \\ MA, USA; ${ }^{2}$ Daiichi Sankyo, Inc., Basking \\ Ridge, NJ, USA; ${ }^{3}$ Department of \\ Anesthesia and Perioperative Care, \\ Rutgers New Jersey Medical School, \\ Newark, NJ, USA
}

Correspondence: Razmic Gregorian Simon-Kucher \& Partners, Strategy and Marketing Consultants, LLC, 20I

Washington Street, Suite 330I, Boston, MA 02108, USA

Tel +|6|7-23|-4500

Fax +|6|7-576-275|

Email Razmic.Gregorian@simon-kucher.com
Objective: To evaluate knowledge, practices, and beliefs of US patients receiving prescription opioids regarding opioid storage, disposal, and diversion.

Design: Internet-based, cross-sectional survey conducted between September and October 2018. Fisher's exact tests and Kendall's Tau-c were used to assess associations with storage and disposal outcomes.

Participants: Patients aged $\geq 18$ years with acute $(n=250)$ or chronic noncancer $(n=250)$ pain were prescribed an oral opioid within 90 days of the survey.

Results: Mean (SD) patient age was 48 (14.7) years, 57.2\% were female, $82.6 \%$ lived with $\geq 1$ person in the home, and $28.0 \%$ had remaining/unused pills. One-third of all patients received safe opioid storage $(35.2 \%)$ and/or disposal $(31.4 \%)$ counseling from a healthcare provider, while $50.0 \%$ received neither storage nor disposal information. Only $27.4 \%$ of all patients stored their opioids in a locked location, and $17.9 \%$ of those with remaining/unused pills disposed of their medication. Patients who received any opioid counseling were more likely to keep their medication in a locked location compared with those who did not $(42.4 \%$ vs $12.4 \%$, respectively; $P<0.0001$ ), as were those who perceived any risk of opioid diversion in the home compared with those who perceived no risk or were unsure $(53.7 \%$ vs $24.2 \%$, respectively; $P<0.0001)$. Disposal rates did not differ based on counseling received $(20.8 \%$ counseled vs $16.1 \%$ not counseled; $P=0.5011)$ or perceived diversion risk $(27.8 \%$ perceived any risk vs $16.4 \%$ perceived no risk or unsure; $P=0.3166$ ).

Conclusion: The proportion of patients receiving prescription opioids who receive safe storage/disposal counseling from a healthcare provider appears suboptimal. Further research is warranted to develop effective ways to improve patient opioid storage/disposal education and practices.

Keywords: surveys, misuse, diversion, abuse, opioids

\section{Introduction}

Between 2006 and 2017, an estimated 233.7 million opioid prescriptions were dispensed annually in the United States; this is comparable to 211.0 billion $\mathrm{mg}$ of morphine equivalents per year. ${ }^{1}$ In $2017,36 \%$ of the 47,600 reported US opioid

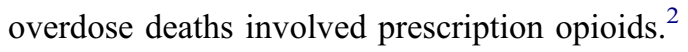

Although prescription opioids play an important role in the treatment of pain, unused drugs are often diverted for nonmedical use and contribute to the misuse and abuse of these products. ${ }^{3}$ Misuse is defined as drugs taken for a purpose other than that directed by the prescribing physician, in greater amounts, more often, or for a longer duration than prescribed. ${ }^{1}$ Results from the 2017 National Survey on Drug Use and Health indicate that nearly 11.4 million US residents misused prescription opioids in the previous year, 
with $53 \%$ obtaining opioids from friends or family (ie, they bought, took, or were given opioids). ${ }^{4} \mathrm{~A}$ recent case-control study of 2303 individuals with opioid overdose and 9212 matched controls showed that the odds of overdose among individuals of all ages (children, adolescents, adults) who themselves did not have an opioid prescription increased almost threefold when family members were being prescribed opioids (odds ratio [OR] 2.89, 95\% confidence interval [CI] 2.59-3.23). ${ }^{5}$ Thus, prescription opioid diversion and misuse present a challenge across multiple levels of society, from families and households to public health and medical systems. ${ }^{6}$

Prior research indicates that keeping unused medication is common practice for patients, as is storing unused medication in unlocked locations. ${ }^{3,7,8}$ A 2019 US cross-sectional study of patients with opioid prescriptions $(\mathrm{N}=152)$ found that only onethird disposed of their unused opioids. ${ }^{8}$ Similarly, according to a 2015 national survey of US adults with recent opioid prescriptions $(\mathrm{N}=1032)$, nearly two-thirds of patients kept or planned to keep unused opioids for future use. ${ }^{7}$ A 2016 systematic review of 6 US studies across 7 different types of surgery concluded that patients seldom stored and disposed of opioids properly: $73 \%$ to $77 \%$ stored opioids in unlocked locations, $67 \%$ to $92 \%$ had unused prescription opioids, and only $4 \%$ to $30 \%$ disposed of or planned to dispose of unused prescription opioids. ${ }^{3}$ These practices leave ample opportunity for opioid diversion and contribute to the epidemic of opioid overdose and death. ${ }^{7,9,10}$

Regulatory actions at the federal and state levels have sought to limit access to unused medications while still ensuring effective pain management. ${ }^{11}$ The US Food and Drug Administration (FDA) Opioid Analgesic Risk Evaluation and Management Strategy (REMS) program, approved in September 2018, requires that training be provided to all healthcare providers involved in patient pain management. ${ }^{12}$ This training includes fundamental concepts of pain management, strategies to identify risk factors for addiction and abuse, and best practices for counseling patients on the safe use of opioids. ${ }^{12,13}$ Several states have implemented legislation limiting the supply and/or dose of initial opioid prescriptions and have initiated drug take-back programs. ${ }^{11}$ In addition, the importance of interventions targeting opioid prescription diversion at the patient/provider level has been highlighted in the literature. ${ }^{7,11,14-16}$ This includes the need for patient/caregiver education on opioid misuse and diversion risk and proper opioid storage and disposal, as well as strategies for healthcare providers to reduce the quantity of prescribed pills and identify the signs and symptoms of addiction and abuse among their patients.
Research regarding the frequency of healthcare provider counseling of patients on opioid storage and disposal, and patient practices for storing and disposing of their opioid pain medication, remains limited. Currently available research from a national survey of US adults with opioid prescriptions suggests that nearly half of patients with opioid prescriptions do not receive any healthcare provider counseling on opioid storage $(48.7 \%)$ or disposal $(45.3 \%){ }^{7}$ Therefore, this survey study seeks to evaluate the following among patients who received prescription opioids for the treatment of acute or chronic pain: 1) knowledge and practice of safe opioid storage and disposal and 2) beliefs regarding prescription opioid diversion.

\section{Methods Survey Objectives}

The objectives of this online cross-sectional survey were to understand patients' prescription opioid storage practices, their handling and disposal practices for unused opioids, and their general perceptions and beliefs about prescription opioid diversion.

\section{Survey Participants and Sampling}

Survey participants were recruited from a third-party market research consumer panel (Research Now SSI, Plano, TX) in the United States. The panel included respondents who had indicated their willingness to participate in internet-based surveys by opting in and confirming their identity during initial enrollment. A patient screening questionnaire restricted the sample to adults $\geq 18$ years of age who had experienced either acute pain (resulting from surgery or injury) or chronic pain (lasting $>90$ days) within 90 days before the survey, and who had been prescribed an oral opioid product containing codeine, hydrocodone, hydromorphone, morphine, oxycodone, oxymorphone, or tapentadol. The opioid prescription must have been filled and stored at home. Patients were excluded if they had both acute and chronic pain conditions, had both an injury and an unrelated surgery, were cancer patients, were taking $>2$ oral opioid products, or were residing in Vermont (due to legislative restrictions on conducting research).

\section{Survey Development}

The survey was developed by the authors in collaboration with a pain management physician and a chronic pain patient affiliated with a national chronic pain advocacy group. The survey was designed to take 30 to $40 \mathrm{mins}$ to complete. Because this study was intended to be 
descriptive rather than inferential, reliability or validity testing was not performed prior to fielding.

\section{Survey Administration}

Invitations were emailed to a random sample of the market research panel until survey segment quotas were met (ie, 250 patients reporting an acute pain condition and 250 patients reporting a chronic pain condition for which opioids were prescribed). As a participation incentive, respondents earned "survey points" that could be redeemed for rewards at a value and rate consistent with the practices of the market research provider. Patients provided informed consent electronically prior to survey participation. The content and process of obtaining informed consent were in accordance with applicable HIPAA (Health Insurance Portability and Accountability Act) and other regulatory requirements. All survey data were de-identified and captured electronically. The study was approved by Institutional Review Board Company, Inc. (Buena Park, CA).

\section{Data Analysis}

A sample size $(\mathrm{N}=500)$ was calculated to capture statistically significant information and to detect an $8 \%$ difference in proportions with $95 \%$ confidence and $80 \%$ power. Descriptive statistics were used to summarize and compare participant data. $T$ tests and Fisher's exact tests were used to assess differences across means and proportions, respectively. Kendall's Tau-c was used to describe the strength of association between patient characteristics and outcomes. $P$ values $<0.05$ were considered statistically significant. Analyses were performed using SAS version 9.2 (SAS Institute, Cary, NC).

\section{Results}

The survey was fielded between September 24, 2018, and October 15, 2018. A total of 500 patients, including 250 patients receiving treatment for acute pain and 250 receiving treatment for chronic pain, completed the survey. The mean (standard deviation [SD]) patient age was 48.2 (14.7) years, $57.2 \%$ were female, and $82.6 \%$ resided with $\geq 1$ other person in the household (Table 1). Prescriptions for products containing hydrocodone or oxycodone were the most frequently reported opioids for the management of pain, with a significantly higher proportion of patients with chronic pain receiving hydrocodone-containing products than patients with acute pain $(P<0.0001)$. At the time of the survey, $28.0 \%$ of patients had unused opioids (ie, had never taken their medication [5.4\%] or had leftover pills after reporting that they no longer take their medication [22.6\%]) (Figure 1). The mean (SD) number of leftover pills was 15 (13.1).

\section{Patient Perceptions About Opioid Diversion}

Patients were asked whether they believed there was any risk that the prescription opioid medication kept in their home could be taken or used by someone else without their permission (responses: Yes/No/I do not know). Most patients $(86.8 \%)$ perceived no risk of opioid diversion in their household, whereas $10.8 \%$ perceived at least some risk; $2.4 \%$ were uncertain. There were no significant differences between patients with acute versus chronic pain in terms of risk perception for household opioid diversion. Patients who perceived at least some risk $(n=54)$ were asked a theoretical question about the most effective ways to reduce opioid diversion generally, and rated the following options on a scale of 0 (not effective) to 100 (extremely effective) points: disposing of any leftover prescription opioid medication (mean \pm SD: $72.6 \pm 23.7$ ), storing the prescription opioid medication in a locked location (71.7 \pm 22.9$)$, and receiving fewer pills with each prescription $(66.9 \pm 28.3)$.

\section{Storage and Disposal Counseling}

Approximately one-third of patients reported receiving information from their healthcare provider on safe storage $(35.2 \%)$ and/or disposal (31.4\%) of their opioids, while $50.0 \%$ received neither storage nor disposal information (Figure 2). Among the 250 patients counseled, $65.6 \%$ reported receiving the information from a physician, $30.4 \%$ from a nurse, and/or 32.0\% from a pharmacist. The most common form of counseling was verbal $(81.2 \%)$, while $49.2 \%$ of patients received printed materials, and 7.6\% received information from electronic sources. A significantly lower proportion of patients with acute versus chronic pain received storage counseling (28.8\% vs $41.6 \%$; $P=0.0027$ ); however, having been counseled on opioid disposal did not statistically differ by pain type (Figure 2).

Among patients who received storage information, most were counseled to store their opioids in a concealed $(60.2 \%)$ and/or locked (47.7\%) location. Among those who received disposal information, most were advised to dispose of their medication via take-back programs (59.2\%) and/or other authorized centers (eg, Drug Enforcement Administrationapproved retail, hospital, or clinic pharmacies, or law enforcement facilities) $(56.1 \%)$; one-quarter $(24.8 \%)$ reported that 
Table I Patient Characteristics

\begin{tabular}{|c|c|c|c|c|}
\hline Characteristics & $\begin{array}{l}\text { All } \\
N=500\end{array}$ & $\begin{array}{l}\text { Acute Pain } \\
n=250\end{array}$ & $\begin{array}{l}\text { Chronic } \\
\text { Pain } \\
\text { n=250 }\end{array}$ & $P$ value \\
\hline Age, mean (SD), y & $48.2(14.7)$ & $47.3(15.5)$ & $49.0(13.6)$ & 0.1884 \\
\hline Female, n (\%) & $286(57.2)$ & $135(54.0)$ & $15 \mid(60.4)$ & 0.1751 \\
\hline Region, n (\%) & & & & 0.5234 \\
\hline Northeast & $95(19.0)$ & $49(19.6)$ & $46(18.4)$ & \\
\hline Midwest & $132(26.4)$ & $68(27.2)$ & $64(25.6)$ & \\
\hline South & $159(31.8)$ & $83(33.2)$ & $76(30.4)$ & \\
\hline West & $114(22.8)$ & $50(20.0)$ & $64(25.6)$ & \\
\hline Patient Lives, n (\%) & & & & 0.0296 \\
\hline Alone & $87(17.4)$ & $45(18.0)$ & $42(16.8)$ & \\
\hline With I other & $168(33.6)$ & $98(39.2)$ & $70(28.0)$ & \\
\hline With 2 others & $102(20.4)$ & $50(20.0)$ & $52(20.8)$ & \\
\hline With 3 others & $72(14.4)$ & $28(11.2)$ & $44(17.6)$ & \\
\hline With 4+ others & $71(14.2)$ & $29(11.6)$ & $42(16.8)$ & \\
\hline \multicolumn{5}{|l|}{ Opioid Received, n (\%) } \\
\hline Hydrocodone ${ }^{\mathrm{b}}$ & $335(67.0)$ & $142(56.8)$ & $193(77.2)$ & $<0.0001$ \\
\hline Oxycodone $e^{b}$ & $183(36.6)$ & $106(42.4)$ & $77(30.8)$ & 0.0071 \\
\hline Codeine $^{b}$ & $49(9.8)$ & $21(8.4)$ & $28(11.2)$ & 0.2924 \\
\hline Morphine & $38(7.6)$ & $25(10.0)$ & $13(5.2)$ & 0.0429 \\
\hline Hydromorphone & $19(3.8)$ & $12(4.8)$ & $7(2.8)$ & 0.2422 \\
\hline Tapentadol & $13(2.6)$ & $2(0.8)$ & II (4.4) & 0.0114 \\
\hline Oxymorphone & $5(1.0)$ & $3(1.2)$ & $2(0.8)$ & 0.6531 \\
\hline
\end{tabular}

Notes: ${ }^{a} 67 \%$ from surgery; $32 \%$ from injury, ${ }^{b}$ single-entity or combination product.

mixing with household trash was presented as an option. A small proportion of patients $(12.7 \%)$ were advised to dispose of their medication via flushing.

\section{Storage and Disposal Practices}

In practice, $27.4 \%$ of all patients stored their opioids in a locked location, $46.6 \%$ in a concealed location, and $26.0 \%$ in an open location (Figure 3). Opioid storage

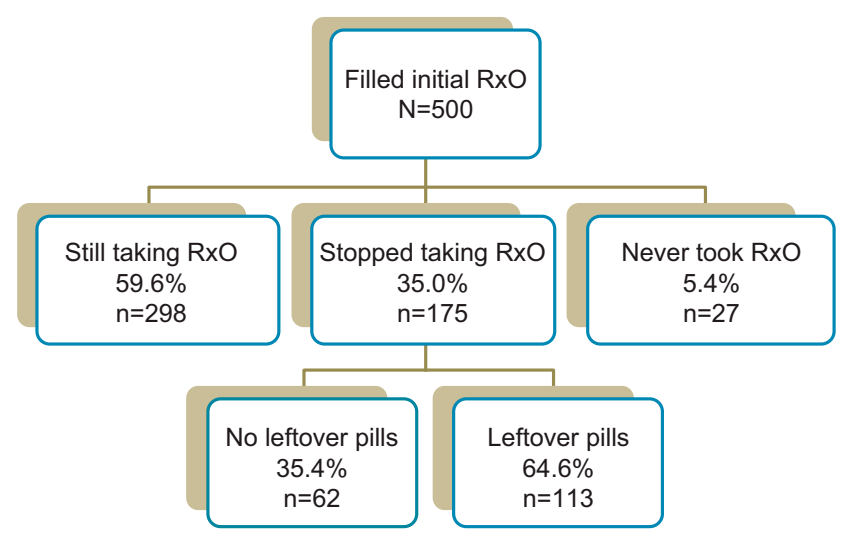

Figure I Patients' opioid prescription status at the time of survey. Abbreviation: $\mathrm{RxO}$, prescription opioid.

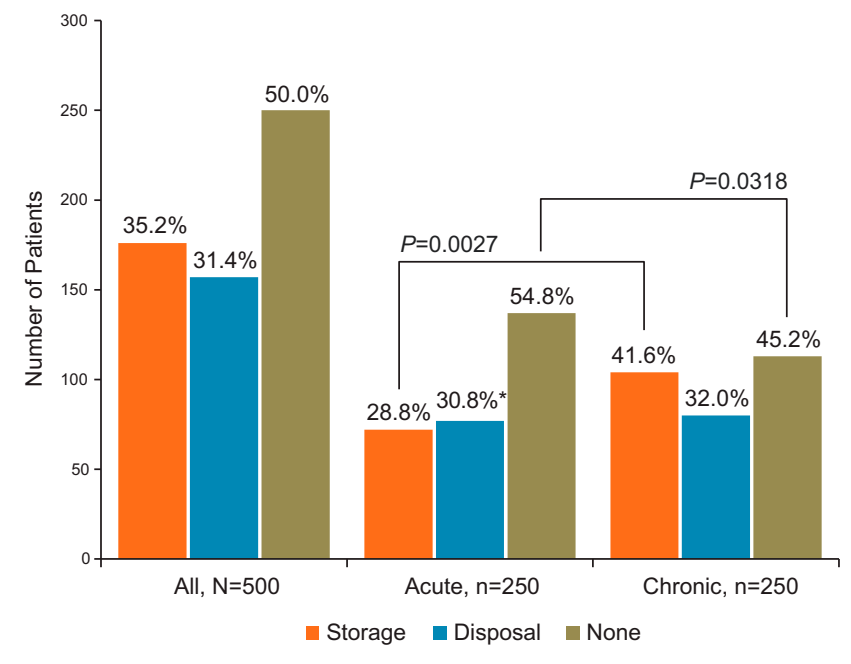

Figure 2 Proportion of patients who received counseling on safe opioid storage and/or disposal from a healthcare provider. Q: Which of the following, if any, did a healthcare professional (eg, nurse, doctor, hospital staff member) provide information to you on when given the prescription for opioid medication? *Rates of opioid disposal counseling did not statistically differ between patients treated for acute versus chronic pain.

behavior differed significantly for patients with acute versus chronic pain, with patients with acute pain being more likely to store their medication in an open location $(32.0 \%$ vs $20.0 \%$ ) and less likely to store in a locked location (22.8\% vs $32.0 \%)(P=0.0045)$. Patients who reported storing their opioids in an open or concealed unlocked location $(n=354)$ were asked their reasons for doing so. The majority reported that they did not lock because they were not worried about anyone taking their medication (Table 2). Other reasons included not having access to a locked location in the home and inconvenience.

Of the 140 patients with unused medication (Figure 1), only $17.9 \%$ disposed of their opioids and $79.3 \%$ still had them in their possession (Figure 4). Opioid disposal behavior differed significantly between patients with acute versus chronic pain with $21.0 \%$ and $0 \%$ disposing of their medication, respectively $(P<0.0001)$. Overall, the most frequently cited reason for keeping unused opioids was to save them for future personal needs (Table 2). Other reasons included not being instructed to dispose of unused opioids and/or not knowing how to dispose of them properly.

\section{Factors Associated with Opioid Storage and Disposal}

Receipt of any opioid storage and/or disposal counseling was significantly associated with patient storage practices: a higher percentage of patients who received any counseling stored their opioids in a locked location versus those 


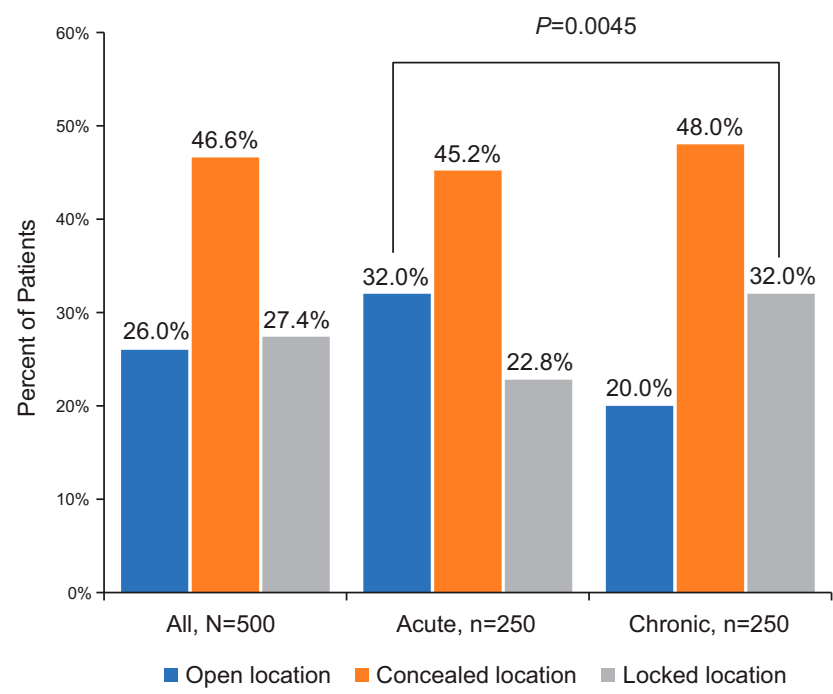

Figure 3 Distribution of opioid storage behavior. Q: Where did you store the prescription opioid medication?

who did not receive any counseling $(P<0.00001)$ (Table 3$)$. In addition, patients with chronic pain were significantly more likely to store their opioids in a locked location than patients with acute pain $(P=0.0278)$, as were those who perceived risk of diversion in their household versus those who did not or were unsure $(P<0.00001)$. Other factors associated with an increased likelihood of locked storage behavior included patients aged between 25 and 54 years ( $P=0.0011)$, larger household size $(P=0.00008)$, and having been counseled on both opioid storage and disposal by a healthcare provider $(P=0.0266)$. Opioid disposal rates only differed by pain type; ie, patients with acute pain were significantly more likely to dispose of their unused medication compared with those with chronic pain $(P=0.0205)$.

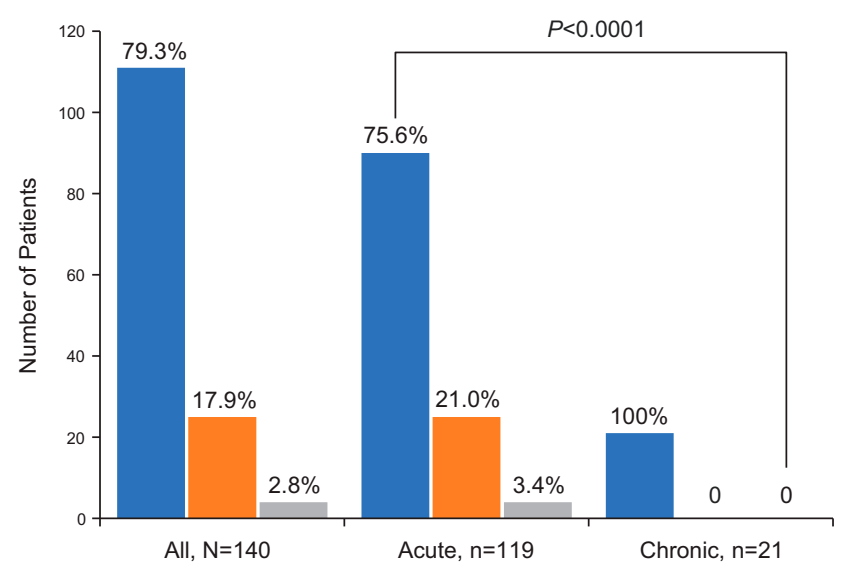

n Still have medication Disposed of medication $\quad$ Other

Figure 4 Distribution of patient opioid disposal behavior among patients with unused opioids $(\mathrm{N}=140)$. Q: What did you do with any leftover pills from your prescription opioid medication?

\section{Factors Associated with Perceived Risk of Opioid Diversion}

Perceived risk of opioid diversion in the home significantly differed by age $(P=0.0008)$. Patients were most likely to perceive risk if they were aged 25 to 34 years $(15 \%)$ and 35 to 44 years $(20 \%)$. Older age groups perceived the least risk (55-64 years, 5\%; $\geq 65$ years, $2 \%$ ). Males were significantly more likely to perceive diversion risk compared with females $(18 \%$ vs $6 \%$; $P<0.0001)$. In addition, patients who reported the presence of children in their households were significantly more likely to perceive opioid diversion risk (17\%) compared with those living in adults-only households $(3 \%)(P<0.0001)$. Other factors significantly associated with a higher likelihood of perceived diversion risk included having received any opioid storage and/or disposal counseling (18\%) versus no

Table 2 Reported Reasons for Not Storing Opioids in a Locked Location and Not Disposing of Unused Opioids

\begin{tabular}{|c|c|c|c|c|}
\hline & Overall & Acute & Chronic & $P$ value \\
\hline Reasons for Not Storing Opioids in a Locked Location, n (\%) & $N=354$ & $n=190$ & $n=164$ & \\
\hline Not worried about anyone taking medication & $278(78.5)$ & $150(78.9)$ & $128(78.0)$ & 0.0477 \\
\hline No access to a locked location & $80(22.6)$ & $4 \mid(2 \mid .6)$ & $39(23.8)$ & 0.8073 \\
\hline Inconvenient & $29(8.2)$ & $15(7.9)$ & $14(8.5)$ & 0.8483 \\
\hline Other & $12(3.4)$ & $7(3.7)$ & $5(3.0)$ & 0.5589 \\
\hline Reasons for Not Disposing of Unused Opioids, $\mathrm{n}(\%)^{\mathrm{a}}$ & $n=111$ & $\mathrm{n}=90$ & $n=21$ & \\
\hline Save for future need & $70(63.1)$ & $54(60.0)$ & $16(76.0)$ & $<0.0001$ \\
\hline Not told to dispose & $19(17.1)$ & $16(17.8)$ & $3(14.3)$ & 0.0024 \\
\hline Do not know how to dispose & II (9.9) & II (I2.2) & 0 & 0.0008 \\
\hline Save for family/friend need & $5(4.5)$ & $4(4.4)$ & I (4.8) & 0.1775 \\
\hline Inconvenient & $5(4.5)$ & $3(3.3)$ & $2(9.5)$ & 0.6531 \\
\hline Other & II (9.9) & $10(11.1)$ & I (4.8) & 0.0061 \\
\hline
\end{tabular}

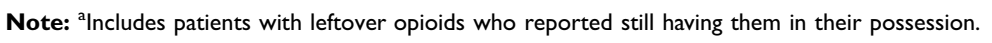


Table 3 Effect of Patient Factors on Opioid Storage and Disposal

\begin{tabular}{|c|c|c|c|c|}
\hline Characteristics & $\begin{array}{l}\text { Stored Opioids in Locked } \\
\text { Location, n (\%) }\end{array}$ & $P$ value & $\begin{array}{l}\text { Disposed of Unused } \\
\text { Opioids, n (\%) }\end{array}$ & $P$ value \\
\hline $\begin{array}{l}\text { Patient Age, } y \\
\qquad \begin{array}{l}\text { I8-24 (S: } n=21 ; D: n=9) \\
\text { 25-34 (S: } n=89 ; D: n=22) \\
\text { 35-44 (S: } n=109 ; D: n=28) \\
\text { 45-54 (S: } n=90 ; D: n=25) \\
55-64 \text { (S: } n=107 ; D: n=25) \\
65+(S: n=84 ; D: n=31)\end{array}\end{array}$ & $\begin{array}{l}4(19.0) \\
34(38.2) \\
38(34.9) \\
28(31.1) \\
19(17.8) \\
14(16.7)\end{array}$ & 0.0011 & $\begin{array}{l}3(33.3) \\
3(13.6) \\
6(21.4) \\
3(12.0) \\
4(16.0) \\
6(19.4)\end{array}$ & 0.7677 \\
\hline $\begin{array}{l}\text { Lives Alone or with Others } \\
\text { Alone (S: } n=87 \text {; }: n=27) \\
\text { With I other (S: } n=168 ; D: n=56) \\
\text { With } 2 \text { others (S: } n=102 ; D: n=2 I) \\
\text { With } 3 \text { others (S: } n=72 ; D: n=21 \text { ) } \\
\text { With } 4+\text { others (S: } n=7 \mid \text { I } D: n=15)\end{array}$ & $\begin{array}{l}21(24.1) \\
30(17.9) \\
30(29.4) \\
26(36.1) \\
30(42.3)\end{array}$ & 0.00008 & $\begin{array}{l}6(22.2) \\
10(17.9) \\
2(9.5) \\
1(4.8) \\
6(40.0)\end{array}$ & 0.0619 \\
\hline $\begin{array}{l}\text { Pain type } \\
\text { Acute (S: } n=250 ; D: n=119) \\
\text { Chronic (S: } n=250 ; D: n=21)\end{array}$ & $\begin{array}{l}57(22.8) \\
80(32.0)\end{array}$ & 0.0278 & $\begin{array}{l}25(21.0) \\
0(0)\end{array}$ & 0.0205 \\
\hline $\begin{array}{l}\text { Perceived Risk of Diversion in } \\
\text { Household } \\
\text { Yes (S: } n=54 \text {; } D: n=18 \text { ) } \\
\text { No or unsure (S: } n=446 \text {; D: } n=122 \text { ) }\end{array}$ & $\begin{array}{l}29(53.7) \\
108(24.2)\end{array}$ & $<0.00001$ & $\begin{array}{l}5(27.8) \\
20(16.4)\end{array}$ & 0.3166 \\
\hline $\begin{array}{l}\text { Received any Counseling on Opioid } \\
\text { Storage/disposal } \\
\text { Yes (S: } n=250 ; D: n=53) \\
\text { No (S: } n=250 ; D: n=87)\end{array}$ & $\begin{array}{l}106(42.4) \\
31(12.4)\end{array}$ & $<0.00001$ & $\begin{array}{l}\text { II (20.8) } \\
\text { I4 (I6.1) }\end{array}$ & 0.5011 \\
\hline $\begin{array}{l}\text { Type of Counseling } \\
\text { Storage only (S: } n=93 ; D: n=24) \\
\text { Disposal only (S: } n=74 ; D: n=19) \\
\text { Both (S: } n=83 ; D: n=10)\end{array}$ & $\begin{array}{l}35(37.6) \\
26(35.1) \\
45(54.2)\end{array}$ & 0.0266 & $\begin{array}{l}5(20.8) \\
4(21.1) \\
2(20.0)\end{array}$ & 0.9999 \\
\hline
\end{tabular}

Notes: ${ }^{\mathrm{a}}$ Among $\mathrm{n}=140$ patients with leftover medication, bamong patients who received storage and/or disposal counseling. Abbreviations: S, denominators for Storage column; D, denominators for Disposal column.

counseling (4\%) $(P<0.0001)$ and locked opioid storage location $(23 \%)$ versus open $(12 \%)$ or concealed $(3 \%)$ locations $(P<0.0001)$.

Patient perceived risk of diversion and having been counseled on opioid storage and/or disposal were both weakly correlated with opioid storage behavior; however, the latter was not statistically significant (respective correlation coefficients, $0.11[P<0.0001]$ and $0.08[P=0.1068])$.

\section{Discussion}

In this cross-sectional survey of US adults with oral opioid prescriptions, the proportion of patients who received any counseling/information on medication storage or disposal was suboptimal. In practice, a little more than one-quarter $(27.4 \%)$ of all patients stored their opioids in a locked location and less than one-fifth (17.9\%) of patients with unused medication actually disposed of their leftover pills. Nearly four-fifths $(79.3 \%)$ of patients with unused medication still possessed opioids in the home. Patients in this study generally were in fairly high agreement that the implementation of safe storage and disposal methods may help to decrease opioid diversion.

The present survey corroborates prior research indicating that storing opioid prescription medication in an unlocked location is common practice for most patients, as is failing to dispose of unused medications. ${ }^{3,7,8}$ In addition, this study adds to the literature by presenting key information regarding the rationale behind patient opioid storage/disposal behavior, as well as the impact of the perceived risk of diversion on patient behaviors. For 
example, the vast majority of patients who stored their medications in an unlocked location did so because they were not concerned about anyone taking their drugs, despite the fact that most patients resided with $\geq 1$ other individual. Indeed, overall, patients' perception of diversion risk in their own home was low, suggesting a lack of awareness regarding potential internal and external risks (eg, guests or workers coming into the home). Patients who reported living with children, as well as those aged 35 to 44 years, were most likely to perceive the risk of diversion. These factors may be correlated because the age groups most likely to perceive diversion risk may also have children at risk of opioid misuse in the home. More research is needed to clarify these relationships and any potential impact on opioid storage/disposal behaviors.

In the present survey, a significantly higher proportion of patients who did perceive diversion risk in their household stored their medication in a locked location compared with those who perceived no risk. Moreover, patients in this survey who received any counseling on opioid storage/disposal stored their medication in a locked location at a higher rate than those who did not receive counseling. There may be a relationship between perceived risk and the receipt of opioid storage/disposal counseling, such that patients' perceived risk is heightened by virtue of having received counseling from their provider. More research is needed to understand if any such relationship exists.

The most frequently cited reason for not disposing of unused medication was saving pills for future use, especially among patients with chronic pain, suggesting that patients find utility in keeping their unused opioids. This was true for patients surveyed by Kennedy-Hendricks et al as well; $61.3 \%$ of patients kept or planned to keep unused opioids for future use. ${ }^{7}$ Similarly, in the cross-sectional study conducted by Buffington et al, the most common driver of keeping unused opioids was the desire to have it on hand for future pain needs. ${ }^{8}$ Indeed, because no patients with chronic pain in the present survey disposed of their medication, pain type was significantly associated with drug disposal.

The next most frequently cited reason in the present survey for not disposing of opioids was not being told to do so. However, there was no significant difference in disposal practices between patients who did and did not receive disposal counseling. This differs from findings in Buffington et al: Education regarding the importance of and the appropriate methods for drug disposal was associated with a significantly increased likelihood that patients reported disposing of unused opioids. Among patients who received information about appropriate opioid disposal, $56.4 \%$ disposed of their opioids, and $19.6 \%$ did not $(P<0.0001) .^{8}$

The combination of unsafe opioid storage practices and undisposed drug within the household, evident in this survey and the literature, ${ }^{3,7,8}$ suggests a stockpile of unused and available prescription opioids and sets the stage for potential opioid misuse and diversion. The US government has sought to address this issue via the FDA Education Blueprint for Health Care Providers Involved in the Treatment and Monitoring of Patients with Pain ("FDA Blueprint"). The FDA Blueprint, created in September 2018 and developed as part of the federal Opioid Analgesic REMS program, includes as a core educational objective "how to counsel patients and caregivers about the safe use of opioid analgesics, including proper storage and disposal."13 The FDA Blueprint also provides physicians with information on how to counsel patients on "risks of theft by family members and household visitors." 13 In addition, the US Centers for Disease Control and Prevention (CDC) has developed an online module to increase healthcare providers' knowledge of recommended strategies for effective communication with patients about opioid use. While the FDA Blueprint and the CDC module are important steps towards mitigating the opioid crisis, the need for patient education on medication storage and disposal is not limited to opioids. Providing patients with information on proper storage and disposal of all prescribed medications would increase the number of patient touch-points and may improve medication safety practices in the home overall. In Buffington et al, the greatest influence in patients' disposing of unused opioids was their having a routine practice of disposing of all unused prescription medications. ${ }^{8}$

In addition, the role of pharmacists, nurses, and other physician extenders in providing safe opioid storage and disposal counseling should not be overlooked. Notably, of those patients in the present survey who did receive any storage or disposal counseling, nearly a third received such education from either a nurse $(30.4 \%)$ and/or a pharmacist (32\%). Similarly, in the survey conducted by KennedyHendricks et al, $44.1 \%$ and $34.7 \%$ of patients who received counseling on opioid storage and disposal, respectively, reported pharmacists as their primary source of information. ${ }^{7}$ With physician-patient contact time being limited, ${ }^{17,18}$ other opportunities to discuss safe opioid practices with patients should be utilized to optimize medication safety practices. 
Finally, increased attention should be paid to providing opioid storage and disposal counseling to patients with acute pain, as this study found that these patients received less information than those with chronic pain. This may be a function of the frequency of contact with healthcare providers. Patients with chronic pain, in theory, interact with pain specialists and other healthcare providers more often than patients with acute pain and may, therefore, be more likely to receive storage and disposal counseling. Indeed, a 2016 population-based Canadian study $(\mathrm{N}=1294)$ found that patients with chronic pain had a higher frequency of physician visits than patients without chronic pain (OR 4.7, 95\% CI 2.8-7.9; $P<0.001) .{ }^{19}$ Further research is needed to understand the reasons for the differences in counseling received by patients with acute versus chronic pain.

This study includes both strengths and limitations. A strength of this research is that it addresses information gaps regarding patient perception of opioid diversion risk, as well as whether and how patients attempt to prevent opioid diversion and misuse in their households. However, this study relied upon patient-reported responses and may be subject to recall and confirmation biases. Similarly, patients may have felt pressured to provide more socially desirable responses (eg, storing opioids in a locked location), thus inflating certain estimates. In addition, patients participating in this survey were identified from an existing market research panel and may not be representative of all patients who use prescription opioids to manage pain. The number of patients in the sample who disposed of their leftover opioid medication was small; therefore, associations with disposal behavior should be interpreted with caution. Finally, due to the observational, cross-sectional nature of this study, cause and effect cannot be determined.

\section{Conclusion}

Results from this survey showed that half of the patients who received an oral opioid prescription did not receive storage or disposal counseling from a healthcare provider. Most patients with unused opioids did not dispose of them - most notably $0 \%$ of patients with chronic pain - suggesting that it may be difficult to remedy opioid disposal practices. Counseling by a healthcare provider, and education addressing the potential for opioid diversion by a household member or visitor, may have a positive impact on safe medication storage practices. Further research aimed at improving the proper storage and disposal of unused medications and general safety surrounding opioids is warranted.

\section{Data Sharing Statement}

Data and survey sharing will be considered upon request. Please contact Elizabeth Marrett at emarrett@dsi.com.

\section{Acknowledgments}

The authors would like to thank Penney Cowan, founder and CEO of the American Chronic Pain Association, for her assistance with survey development.

\section{Author Contributions}

All authors made substantial contributions to study conception and design, acquisition of data, or analysis and interpretation of data; took part in drafting the article or revising it critically for important intellectual content; gave final approval of the version to be published; and agree to be accountable for all aspects of the work.

\section{Funding}

This study was sponsored by Daiichi-Sankyo. Medical editorial assistance was provided by Larry Radican, PhD, MPH, of Peloton Advantage, LLC, an OPEN Health company, and funded by Daiichi-Sankyo.

\section{Disclosure}

Razmic Gregorian and Mariana Torgal are employees of Simon-Kucher \& Partners, Cambridge, MA, who completed the data analysis. Vivek Sivathanu and Sejal Shah are former employees of Simon-Kucher \& Partners, Cambridge, MA, who completed the data analysis. Elizabeth Marrett and Winghan Jacqueline Kwong are employees of Daiichi Sankyo, Inc., Basking Ridge, NJ. Jeffrey Gudin received consulting fees from Daiichi Sankyo, Inc., related to the development of the study protocol and survey. The authors report no other conflicts of interest in this work.

\section{References}

1. Schieber LZ, Guy GP Jr., Seth P, et al. Trends and patterns of geographic variation in opioid prescribing practices by state, United States, 2006-2017. JAMA Netw Open. 2019;2(3):e190665. doi:10.1001/jamanetworkopen.2019.0665

2. Scholl L, Seth P, Kariisa M, Wilson N, Baldwin G. Drug and opioidinvolved overdose deaths - United States, 2013-2017. MMWR Morb Mortal Wkly Rep. 2019;67(5152):1419-1427.

3. Bicket MC, Long JJ, Pronovost PJ, Alexander GC, Wu CL. Prescription opioid analgesics commonly unused after surgery: a systematic review. JAMA Surg. 2017;152(11):1066-1071. doi:10.1001/jamasurg.2017.0831

4. Substance Abuse and Mental Health Services Administration. Key substance use and mental health indicators in the United States: results from the 2017 national survey on drug use and health; 2018. Available from: https://www.samhsa.gov/data/sites/default/files/cbhsq-reports /NSDUHFFR2017/NSDUHFFR2017.pdf. Accessed July 16, 2019. 
5. Khan NF, Bateman BT, Landon JE, Gagne JJ. Association of opioid overdose with opioid prescriptions to family members. JAMA Intern Med. 2019;179(9):1186. doi:10.1001/jamainternmed.2019.1064

6. Daley DC, Smith E, Balogh D, Toscolani J. Forgotten but not gone: the impact of the opioid epidemic and other substance use disorders on families and children. Commonwealth. 2018;20(1):93-121. doi:10.15367/com.v20i2-3.189

7. Kennedy-Hendricks A, Gielen A, McDonald E, McGinty EE, Shields W, Barry CL. Medication sharing, storage, and disposal practices for opioid medications among US adults. JAMA Intern Med. 2016;176(7):1027-1029. doi:10.1001/jamainternmed.2016.2543

8. Buffington DE, Lozicki A, Alfieri T, Bond TC. Understanding factors that contribute to the disposal of unused opioid medication. J Pain Res. 2019;12:725-732. doi:10.2147/JPR.S171742

9. Voepel-Lewis T, Wagner D, Tait AR. Leftover prescription opioids after minor procedures: an unwitting source for accidental overdose in children. JAMA Pediatr. 2015;169(5):497-498. doi:10.1001/jamapediatrics.2014.3583

10. Bailey JE, Campagna E, Dart RC. The underrecognized toll of prescription opioid abuse on young children. Ann Emerg Med. 2009;53 (4):419-424. doi:10.1016/j.annemergmed.2008.07.015

11. Nalamachu SR, Shah B. Abuse of immediate-release opioids and current approaches to reduce misuse, abuse, and diversion. Postgrad Med. 2018;1-7. doi:10.1080/00325481.2018.1502569

12. U. S. Food and Drug Administration. Opioid analgesic risk evaluation and mitigation strategy (REMS); 2018. Available from: https:// www.fda.gov/drugs/information-drug-class/opioid-analgesic-riskevaluation-and-mitigation-strategy-rems. Accessed July 9, 2019.
13. U. S. Food and Drug Administration. FDA education blueprint for health care providers involved in the treatment and monitoring of patients with pain; 2018. Available from: https://www.fda.gov/media/ 99496/download. Accessed July 16, 2019.

14. Han B, Compton WM, Blanco C, Crane E, Lee J, Jones CM. Prescription opioid use, misuse, and use disorders in U.S. adults: 2015 national survey on drug use and health. Ann Intern Med. 2017;167(5):293-301. doi:10.7326/M17-0865

15. Feinberg AE, Chesney TR, Srikandarajah S, Acuna SA, McLeod RS. Opioid use after discharge in postoperative patients: a systematic review. Ann Surg. 2018;267(6):1056-1062. doi:10.1097/SLA.0000000000002591

16. Maughan BC, Hersh EV, Shofer FS, et al. Unused opioid analgesics and drug disposal following outpatient dental surgery: a randomized controlled trial. Drug Alcohol Depend. 2016;168:328-334. doi:10.1016/j.drugalcdep.2016.08.016

17. Young RA, Burge SK, Kumar KA, Wilson JM, Ortiz DF. A timemotion study of primary care physicians' work in the electronic health record era. Fam Med. 2018;50(2):91-99. doi:10.22454/ FamMed.2018.184803

18. Tai-Seale M, McGuire TG, Zhang W. Time allocation in primary care office visits. Health Serv Res. 2007;42(5):1871-1894. doi:10.1111/ j.1475-6773.2006.00689.x

19. Mann EG, Johnson A, Van Den Kerkhof EG. Frequency and characteristics of healthcare visits associated with chronic pain: results from a population-based Canadian study. Can J Anaesth. 2016;63 (4):411-441. doi:10.1007/s12630-015-0578-6
Journal of Pain Research

\section{Publish your work in this journal}

The Journal of Pain Research is an international, peer reviewed, open access, online journal that welcomes laboratory and clinical findings in the fields of pain research and the prevention and management of pain. Original research, reviews, symposium reports, hypothesis formation and commentaries are all considered for publication. The manuscript management system is completely online and includes a very quick and fair peer-review system, which is all easy to use. Visit http:// www.dovepress.com/testimonials.php to read real quotes from published authors. 